\title{
Correlation of Inflammation Mediator Profile Expression Between Tissues and Mucosal in Chronic Rhinosinusitis with Nasal Polyp
}

\author{
Effy Huriyati \\ Otorhinolaryngology Head and Neck Surgery Department, Faculty of Medicine, \\ Andalas University, Padang, West Sumatera, Indonesia
}

\begin{abstract}
There are differences inflammatory patterns in Chronic Rhinosinusitis with Nasal Polyp (CRSwNP) between Caucasians and Asians. One of the most convenient and non-invasive examination tools to find out the inflammatory pattern of CRSwNP is such as mucosal brushing of the polyp. This research investigated the correlation of expression IL-5, IL-8, and IL-17A between the tissue and mucosal polyp.A cross-sectional comparative study involving 15 samples of mucosal brushing and 15 of polyp tissues were performed. We measured IL-5, IL-8, and IL-17A level of mucosal brushing with the Enzyme-Linked Immunosorbent Assay (ELISA) and polyp tissues with immunohistochemistry (IHC) examination. The mean expression of IL-5, IL-8, and IL17 A by IHC was $62.07 \%(\square 26.294), 87.33 \%$ ( $\square 16.969), 88.20 \%$ ( $\square 16.781)$ and ELISA was 0.86 ( $\square 0.13), 1930.60$ ( $\square 879.83), 25.60$ ( $\square 16.969)$. There was no significant relationship between tissue (IHC) and mucosa (ELISA) ( $p>0.05$ ), but in IL-5 expression there was a moderate positive correlation $(0.41<\mathrm{r}<0.60)$. The moderate positive correlation between mucosa and tissue polyp concludes that simple tests such as mucosal brushing can be used to see IL-5 expression in CRSwNP. However, IHC and ELISA tests on IL-8 and IL-17A had negative correlation because there is a variability inflammatory expression between mucosal dan tissues. Mucosal brushing can be used as a simple and non-invasive examination to see IL-5 expression in CRSwNP.
\end{abstract}

Keywords: Chronic Rhinosinusitis with Nasal Polyps, Interleukin-5, Interleukin-8, Interleukin-17a.

\section{Introduction}

Chronic rhinosinusitis (CRS) is a major problem in Otorhinolaryngology, it is one of the chronic diseases that often encountered in the community. Chronic rhinosinusitis is classified based on phenotype types that consist of CRS with polyps (CRSwNP) and CRS without nasal polyps (CRSsNP). Both of these conditions are different in inflammatory pathways, cytokine profile and tissue remodeling. This disease reduces the quality of the patient's life, also causing an economic burden due to the high cost of treatment [1]-[4].

Nasal polyp cases are quite often found, approximately $4 \%$ of the entire population. CRSsNP was around 60\% while CRSwNP was around 20-33\%. The prevalence of CRS in Indonesia is quite high. Based on the data of the ENT Rhinology polyclinic at dr. M. Djamil Hospital Padang, from October 2011 to September 2012, there were 106 new cases of CSR in which 87 cases of CRSsNP and 19 cases of CRSwNP [2],[4],[5]. 
Although there have been many theories and researches about nasal polyps, the exact etiology of nasal polyps and the causes of recurrence are still unknown. Allergic factors are widely studied as etiology of nasal polyps. The presence of inflammatory cells such as eosinophils and mastocytes were found in large numbers at epithelial layer and polyp stromal tissue. The accumulation of collagen accompanied by thickening of smooth muscle cells around the blood vessels and goblet cell hyperplasia was very similar to inflammatory cells also found in people with asthma. In some literature, the eosinophils are predominant cells in nasal polyps [2],[6].

Bachert et al. (2011) examined the levels of several types of cytokines and chemokines in nasal polyps and turbinated in the normal individual. They found the levels of IL-5 were higher in almost all preparations of nasal polyps, whereas it was not found in normal turbinate. In addition, from Immunohistochemistry (IHC) studies, $70 \%$ of cells containing IL-5 was eosinophil cells. It reinforces the alleged autocrine role of IL-5 for eosinophil activation. It concluded that elevated levels of IL-5 cause dominance and activation of eosinophils in nasal polyps and this is a major target for therapy [7].

In Asian populations, nasal polyps were more often accompanied by bacterial infections where neutrophil cells are found. There are only a few kinds of literature that discuss the polyp types in Asian countries. CRSwNP in Caucasians was characterized by dominant Th2 eosinophilic type inflammation with high levels of IL-5, ECP, and local IgE, while CRSwNP in Asian tends to have typical Th1 / Th17 polarization. Characteristic of nasal polyp remodeling of both ethnicities group was albumin accumulation and edema (pseudocysts) in the extracellular matrix. There was a higher concentration of several cytokines associated with Th17 cells such as IL-1b, IL-6, and IL-17A than Th2 cells in CRSwNP in Chinese, though it had a role in chronic upper airway neutrophilic inflammation in Asian population compared to Caucasians [7]-[9].

Patients with nasal polyps often diagnosed at the late stage due to diagnostic difficulties by using conventional techniques such as anterior rhinoscopy with inadequate lighting. This often occurs especially in the polyp stage 1 which is still in the meatus media, making it difficult for early diagnosis, except using nasoendoscopy which is relatively expensive. The exact diagnosis of nasal polyps is based on anatomical pathology appearance of polyp tissue [10]. Therefore, the differences in the histological and inflammatory pattern of CRSwNP still require a further study, It is necessary to find out which method is the most convenient and non-invasive to determine the pattern of inflammatory CRSwNP.

\section{Materials and Methods}

\subsection{Samples}

Samples obtained from CRSwNP patients who had not been undergone surgery before did not use anti-allergic drugs during the washing period, and between aged 18 and 55 years old. Samples were taken by consecutive sampling from all CRSwNP patients who visited the ENT polyclinic of Dr. M. Djamil hospital Padang and willing to participate in the research by filling informed consent forms and had met the inclusion criteria as a research sample, also not included in the exclusion criteria.

\subsection{Sample extraction}


Brushing was performed on the mucosa of nasal polyps with nasoendoscopic guideline in a circular motion with a brushing device in the operating room after the patient was put under general anesthesia. We used a gynecologic cytology brush. Before brushing, cotton tampons containing lidocaine and adrenaline were applied for 10 minutes on the nasal cavity. Brushing was performed in a circular motion ten times with clockwise direction. The sample material was put in a microtube containing $1 \mathrm{ml}$ of saline buffer phosphate (PBS) transport medium. The samples were taken to the Biomedical laboratory, stored in a freezer with a temperature of $-80^{\circ} \mathrm{C}$ which will then be examined by ELISA.

Nasal polyp tissue was collected during surgical removal of polyps by FESS (Functional Endoscopy Sinus Surgery). Polyp tissue was put into neutral formalin liquid and immediately taken to the Anatomy Pathology Laboratory of the Faculty of Medicine, Andalas University Padang for paraffin blocks. If it is not possible to send to Anatomy Pathology Laboratory immediately, the sample was stored in the freezer at $-20^{\circ} \mathrm{C}$ for a maximum of 24 hours at the ENT-HNS Department of Dr. M. Djamil Hospital Padang.

\subsection{ELISA}

All reagents and samples were brought into a room temperature before used. We prepared all reagents, standard dilutions, and samples as directed in ELISA kit. The excess microplate strips were removed from the plate frame, returned to the foil pouch containing the desiccant pack and reseal. One hundred microlitres of assay diluent was added to each well and add $100 \mu \mathrm{L}$ of the sample to each well. All plate incubated at room temperature for 2 hours on a horizontal orbital microplate shaker. Each well was aspirated and washed, the process repeated 3 times for a total of 4 washes. Two hundred microliter of the conjugate was added to each well. All plate was incubated at room temperature for 2 hours on the shaker and then aspirated and washed 4 times. Two hundred microliter substrate solution was added to each well and incubated at room temperature for 30 minutes on the benchtop and protected from light. Fifty microliters of stop solution were added to each well. The result was read at $450 \mathrm{~nm}$ within 30 minutes and the wavelength correction set to $540 \mathrm{~nm}$ or $570 \mathrm{~nm}$.

\subsection{Immunohistochemical}

Paraffin blocks that have been made are collected and labeled according to the PA number and medical record. Paraffin blocks were cut with thicknesses of 4 millimeters. Dried under $37^{\circ} \mathrm{C}$ and warmed up on Slide Warmer with temperature $60^{\circ} \mathrm{C}$. Deparaffinization with xylol I, II, III and rehydration level with alcohol absorbent, $96 \%$ and $80 \%$ alcohol then rinsed with water. Pretreatment with Tris EDTA. Rinsed in PBS with pH 7,4 then blocked the background and was given primary antibody. Rinsed again in PBS with $\mathrm{pH} 7,4$ and add Universal Link, rinsed in PBS with $\mathrm{pH} 7,4$. Add Trekavidin, rinsed in PBS with ph 7,4 rinsed with water and add hematoxylin for counterstain then rinsed again with water. Dilution in Lithium Carbonate (5\% in aquades), rinsed with water and clearing with xylol I, II and III then mount and close it with a cover glass for stabilization of preparations.

Examination of inflammatory mediator expression was carried out based on IHC examination analysis consisting of positive values which are a qualitative calculation and positivity distribution in the form of quantitative calculations; this examination is semiquantitative. A positive value is the result of an assessment of the intensity of the brown color of the epithelium and polyp stroma that appears on the light microscope. 


\subsection{Statistical methods}

SPSS version 17.0.0.0 statistical software was used. The analysis aimed to determine the correlation between immunohistochemistry(tissues) and ELISA (mucosa) examination on IL-5, IL-8, and IL-17A in CRSwNP. Analysis of data normality using the Kolmogorov-Smirnov test. Then the Spearman test was performed to see the correlation between immunohistochemical (tissues) and ELISA (mucosa) examination on IL-5, IL-8, and IL-17A in CRSwNP.

\section{Results}

Research has been conducted on 30 samples from 15 patients CRSwNP who underwent FESS for the first time. This study aims to find the correlation of mediator inflammatory expression between tissues and mucosa of polyps in CRSwNP. There were demographic and clinical characteristics before surgery.

In this study, all samples experienced nasal blockage (100\%), anosmia (93\%), runny nose $(86 \%)$, postnasal drip $(80 \%)$, headache $(86 \%)$ and facial pain $(60 \%)$. In this study, no sample had a history of aspirin sensitivity.

Table 1. Characteristic of sample

\begin{tabular}{|c|c|c|}
\hline & $\mathrm{n}$ & $\%$ \\
\hline \multicolumn{3}{|l|}{ Gender } \\
\hline Male & 10 & 66 \\
\hline Female & 5 & 33 \\
\hline \multicolumn{3}{|l|}{ Age } \\
\hline $\begin{array}{l}\text { Adolescent } \\
(16-<25 \text { years old })\end{array}$ & 3 & 20 \\
\hline $\begin{array}{l}\text { Young Adult } \\
(\geq 25-<35 \text { years old })\end{array}$ & 5 & 33 \\
\hline $\begin{array}{l}\text { Adult } \\
\text { ( } \geq 35-<45 \text { years old) }\end{array}$ & 3 & 20 \\
\hline $\begin{array}{l}\text { Middle age } \\
(\geq 46-<55 \text { years old })\end{array}$ & 4 & 26 \\
\hline \multicolumn{3}{|l|}{ Clinical symptom } \\
\hline Nasal blockage & 15 & 100 \\
\hline Runny nose & 13 & 86 \\
\hline Postnasal drip & 12 & 80 \\
\hline Anosmia & 14 & 93 \\
\hline Facial Pain & 9 & 60 \\
\hline Headache & 13 & 86 \\
\hline \multicolumn{3}{|l|}{ Allergy symptom } \\
\hline Sneezing $>5$ kali & 8 & 53 \\
\hline Rhinitis & 12 & 80 \\
\hline Itchy nose & 6 & 40 \\
\hline Conjunctivitis & 1 & 6 \\
\hline \multicolumn{3}{|l|}{ Atopy } \\
\hline Asthma & 1 & 6 \\
\hline Atopy dermatitis & 3 & 20 \\
\hline
\end{tabular}




\begin{tabular}{lll} 
Aspirin sensitivity & 0 & 0 \\
Smoking & $\mathbf{3}$ & $\mathbf{2 0}$ \\
\hline
\end{tabular}

\subsection{Immunohistochemistry}

Based on the results of immunohistochemistry examination, the average IL-5 expression was $62,1 \%( \pm 26,3)$, IL-8 was $87,3 \%( \pm 16,9)$, and IL-17A was $88,2 \%$ ( $\pm 16,8)$. On the boxplot graph can be seen in the distribution of cytokine expression.

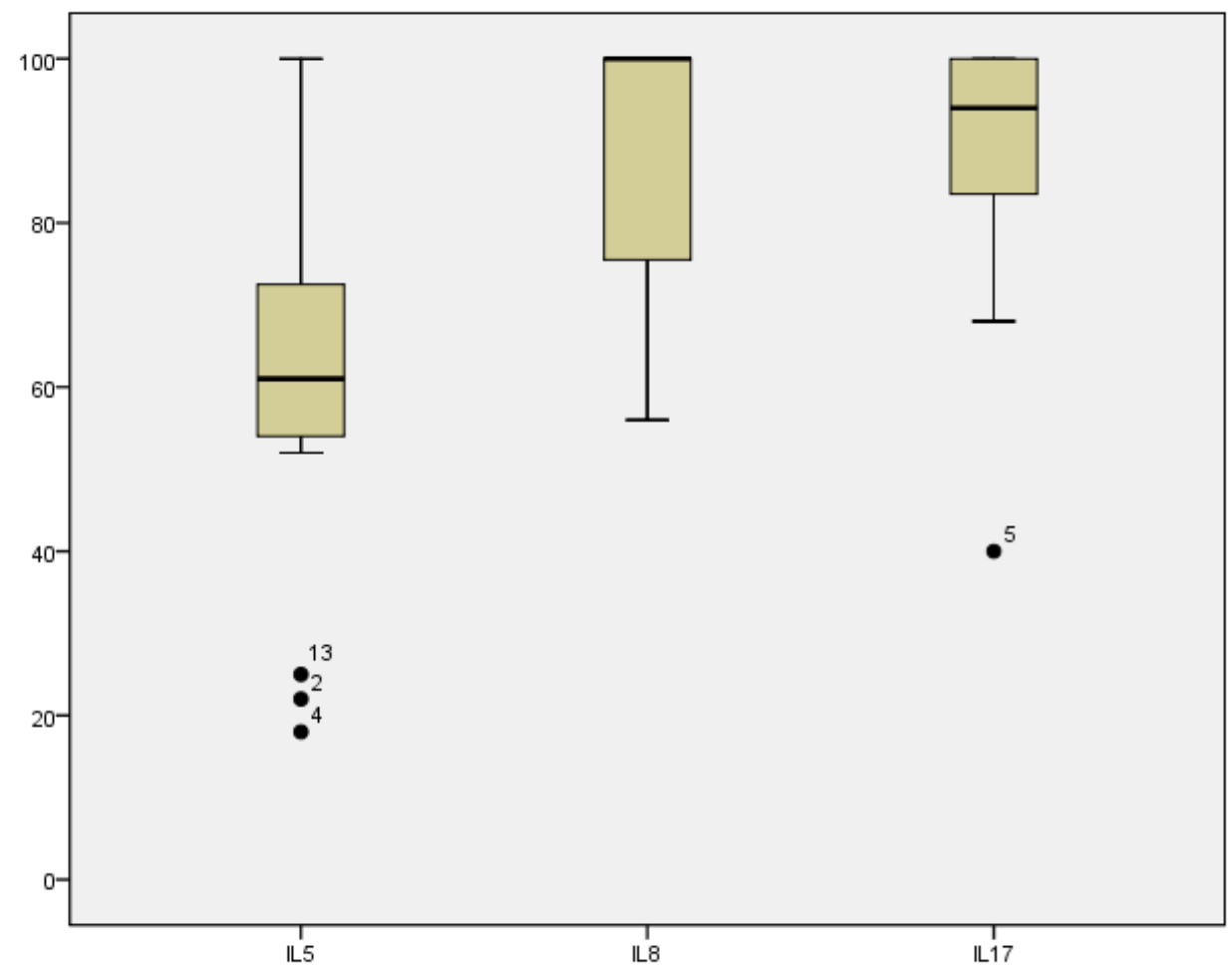

Fig. 1. Distribution of IHC examination of IL-5, IL-8, and IL-17A 


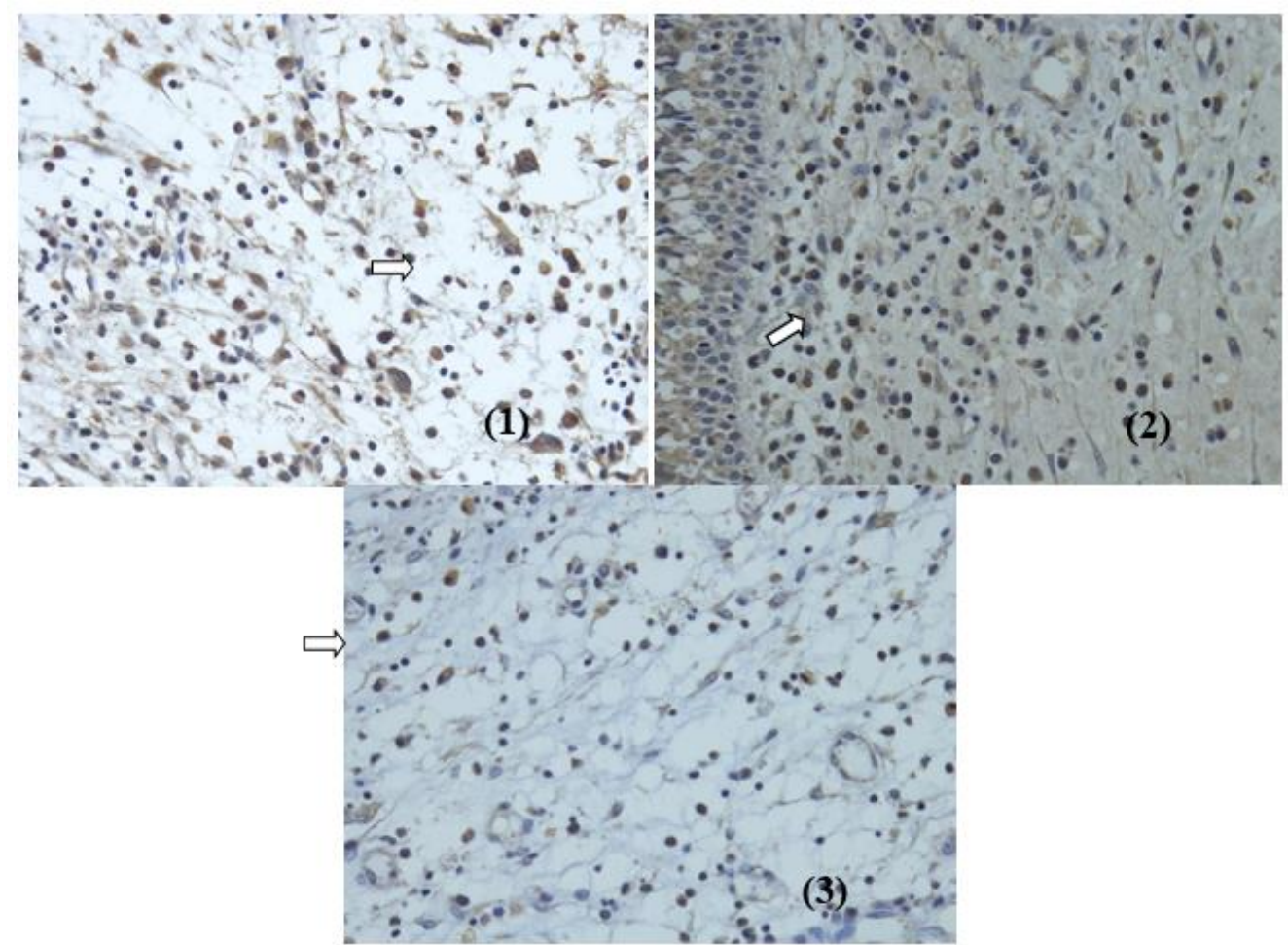

Fig 2. Immunohistochemical of IL-5(1), IL-8(2), and IL-17A(3), the round brown cell was positive and the round blue cell was negative.

\subsection{ELISA}

Based on the results of ELISA examination of mucosal brushing, the average IL-5 expression was $0,9( \pm 0,1)$, IL-8 was $1930.6( \pm 879.8)$ and IL-17A was $25.6( \pm 22.7)$. On the boxplot graph can be seen the distribution of cytokine expression by ELISA examination. 

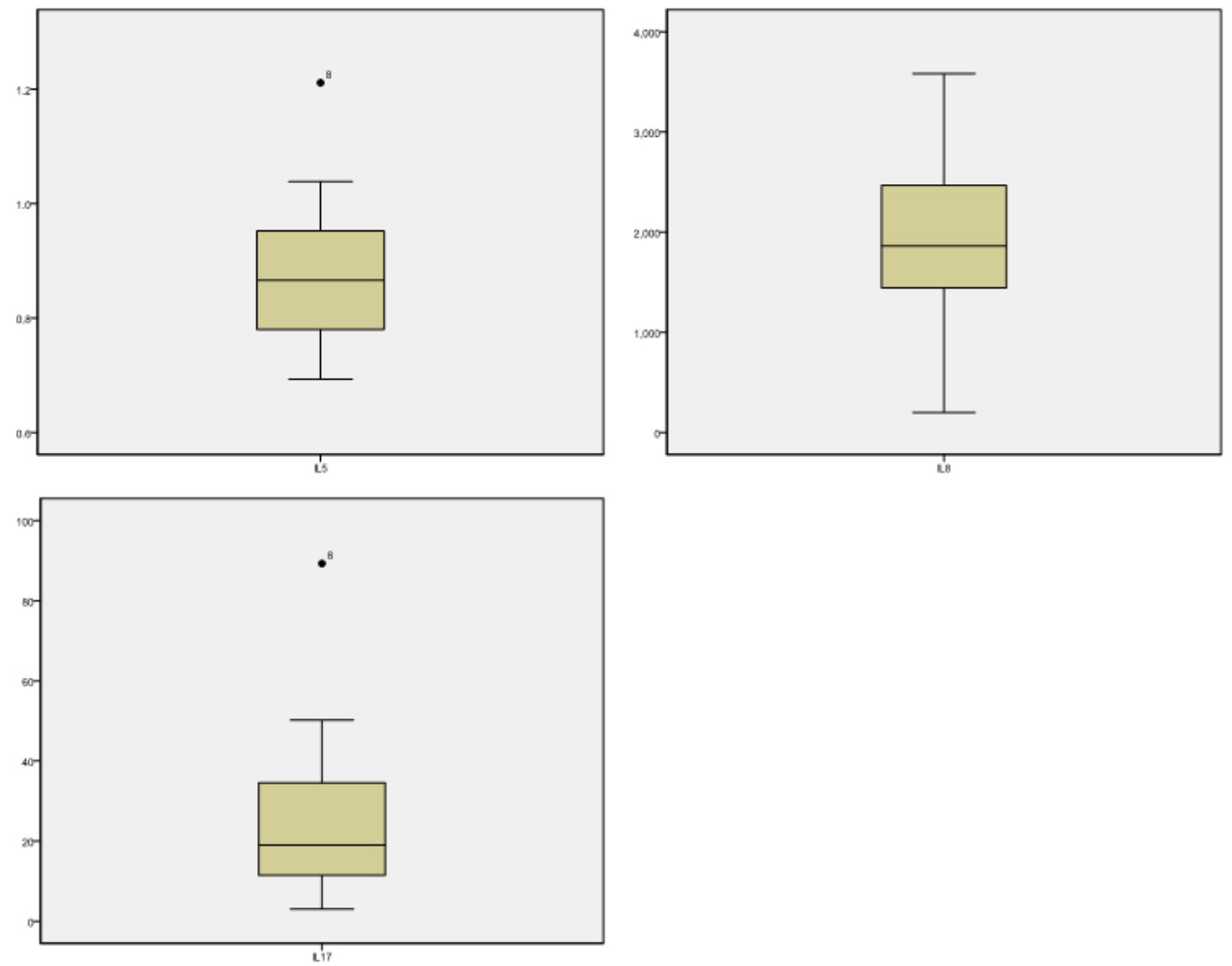

Fig. 3. Boxplot graphs of expression of IL-5, IL-8, and IL-17A on ELISA examination

\subsection{Statistic Analysis}

The analysis test performed with the Kolmogorov-Smirnov test and Spearman test. Data normality test using the Kolmogorov-Smirnov test was $p>0.05$. Therefore, it can be concluded that there was no difference in variance between the groups of data compared. Hence the distribution data was normal; analysis can proceed to the Spearman test to see the correlation between both examination.

\subsection{The correlation between IHC and ELISA examination}

The mean IL-5 expression of IHC was $62.1 \%( \pm 26.3)$ while ELISA was $0.9( \pm 0.1)$. There was no significant relationship between IL-5 expression on the tissue (IHC) and mucosa (ELISA) ( $>0.05$ ). However, there was a moderate positive correlation between tissue and mucosal expression $(0.41<\mathrm{r}<0.60)$. 

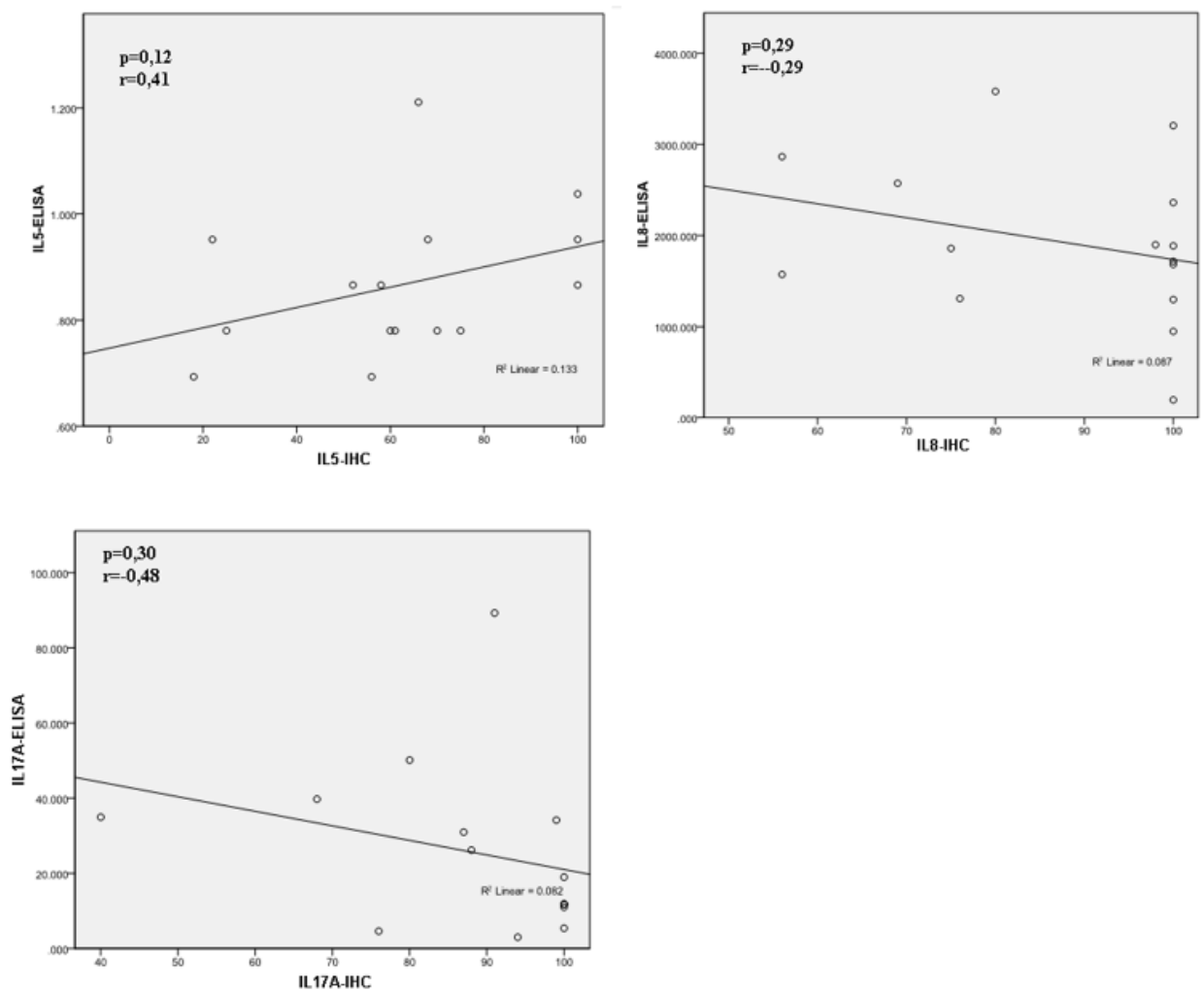

Fig. 4. The correlation between IL-5, IL8, and IL-17A expression between IHC and ELISA examination

The mean IL-8 expression of IHC was $87.3 \%( \pm 16.9)$ while with ELISA was 1930.6 $( \pm 879.8)$. Statistically, there was no significant relationship between tissue (IHC) and mucosa (ELISA) ( $\mathrm{p}>0.05)$. There was a low negative correlation between tissue and mucosal expression $(0.21<r<0.40)$.

The mean IL-17A expression of IHC was $88.2 \%( \pm 16.8)$ and ELISA was $25.6( \pm 16.9)$. There was no significant relationship between IL-17A expression in tissues (IHC) and mucosa (ELISA) ( $p>0.05)$. There was a moderate negative correlation between tissue and mucosal expression $(0.41<\mathrm{r}<0.60)$.

Table 2. Inflammatory mediators in CRSwNP

\begin{tabular}{lllll}
\hline & $\begin{array}{l}\text { IHC } \\
(\boldsymbol{\%})\end{array}$ & $\begin{array}{l}\text { ELISA } \\
(\mathbf{p g} / \mathbf{d l})\end{array}$ & $\mathbf{p}$ & $\mathbf{r}$ \\
\hline IL-5 & $62.1( \pm 26.3)$ & $0.9( \pm 0.1)$ & 0,123 & 0,416 \\
IL-8 & $87.3( \pm 16.9)$ & $1930.6( \pm 879.8)$ & 0,290 & $-0,293$ \\
IL-17A & $88.2( \pm 16.8)$ & $25.6( \pm 22.7)$ & 0,302 & $-0,487$ \\
\hline
\end{tabular}




\section{Discussion}

CRS is an inflammation of the nasal mucosa and paranasal sinuses lasting more than 12 weeks. The diagnosis of rhinosinusitis with or without polyps in adults can be established based on the appearance of symptoms, ENT examination including conventional techniques using anterior rhinoscopy, nasoendoscopy, radiological examination, and anatomical pathology as a definitive examination. Patients with nasal polyps are often diagnosed in the late stages due to diagnostic difficulties [10]-[12].

Extracting polyp tissue was performed under general anesthesia with Functional Endoscopy Sinus Surgery (FESS) techniques or local anesthetics with extirpation techniques. Polyp tissue was extracted for anatomical pathology examination to determine the inflammatory pattern of CRSwNP. In this study, correlation research was conducted between IHC(polyp tissues) and ELISA (brushing mucosa polyp). In this study, the cytokines examined were IL-5, IL-8, and IL17.

The mean of IL-5 expression in IHC was $62.1 \%( \pm 26,3)$ and ELISA was $0.9( \pm 0.1)$. There was no significant relationship between IL-5 expression on the tissue (IHC) and mucosa (ELISA) ( $>$ > 0.05), but there was a positive correlation. Interleukin-5 (IL-5) plays a role in polyp formation. The increase in the cytokines shows predominant T helper 2 (Th2) response. These cytokines have great influence in mechanisms of eosinophil survival and activation. Cascade from the cytokine will increase the infiltration of inflammatory cells, especially eosinophils. Then eosinophils will migrate and encourage the inflammatory process causing stromal fibrosis, epithelial damage, increased edema in the interstitial tissue and increased production of extracellular matrix [13],[14].

Bachert et al. (2010) examined the levels of several cytokines and chemokines in nasal polyps and normal turbinate individual. He found that the levels of IL-5 were higher in almost all preparations of nasal polyps, whereas it is not found in normal individuals Konka. In addition, from immunohistochemistry studies found, $70 \%$ of cells containing IL-5 are eosinophil cells. It strengthens the case of IL-5 autocrine role to the activation of eosinophils. Furthermore, the study found that there is a strong relationship between levels of IL-5 and Eosinophilic Cationic Protein (ECP) which is a marker of eosinophil activation. Therapy with anti IL-5 monoclonal antibodies will cause eosinophil apoptosis and decrease the eosinophil. Bachert's study concluded that elevated levels of IL-5 cause dominance and activation of eosinophils in nasal polyps. However, some polyps do not have many eosinophils but dominated by mononuclear cells as infiltrating cell types. It is not yet well defined. Therefore it needs further investigations to find out the mechanism of formation and development from such mononuclear cell dominant polyps [15],[16].

There have been many studies that already discuss the differences in inflammatory patterns of CRSwNP between Asian and Western populations. Tomassen et al. in 2016 found various inflammatory patterns in Asian ethnicities which there was a role of Th1, Th17 or Th 22. Zhang in 2017 also found that Chinese CRSwNPs patients exhibited Th1 / Th17 polarization with low levels of eosinophil / eosinophilic cationic protein (ECP) leading to neutrophilic inflammation. In another study it concludes that in Asian populations only $16 \%$ expressed IL-5, much lower when compared with a sample of a Belgian population of $83 \%$, IL-5 was identified as a positive determinant for eosinophilic inflammation [2],[15],[17].

In this study, it was found in the analysis test that there was no significant relationship between IL-5 expression on the tissue (IHC) and mucosa (ELISA) ( $p>0.05$ ). However, there was a moderate positive correlation between tissue and mucosal expression $(0.41<\mathrm{r}<0.60)$. It 
can be concluded that the higher ELISA results, the higher IHC examination results, that simple sampling techniques like mucosal brushing can be used to see IL-5 expression in CRSwNP.

On examination of IL-8 expression, the mean IL-8 expression of IHC was $87.3 \%( \pm 16.9)$ while ELISA was $1930.6 \mathrm{pg} / \mathrm{ml}( \pm 879.8)$. In a study conducted by Allen in 1997, it was found that positive IL-8 IHC was examined in all samples and the mean IL-8 RIA (radioimmunoassay) examination was $1767 \mathrm{pg} / \mathrm{ml}( \pm 1633) .{ }^{18}$ In the Asian population, the inflammatory pattern of neutrophilia is characterized by prominent IL-8 expression. Neutrophilic inflammation is characterized by recruitment of neutrophils into sinus effusion mediated by increased regulation of adhesion molecules from the vascular endothelium. Induced by IL-1b and increased secretion of IL-8 from epithelial and neutrophil cells. ${ }^{19}$ Interleukin-8 including chemokines which consists of more than 15 types of proteins and also functioned as chemoattractants and activates neutrophils. IL-8 will stimulate changes in neutrophil form and degranulation, thus releasing elastase, lactoferrin, fibronectin, and others. In addition, IL-8 can stimulate transendothelial neutrophil migration by increasing the regulation of $\alpha 2$ integrins. ${ }^{20}$ Interleukin- 8 is also known can affect the production of MMP-2, MMP-9, and TIMP-1. In the airway epithelium, IL-8 has the potential as an initial activator of MMP-9 during the respiratory tract epithelial regeneration process. Furthermore, interleukin-8 has the ability to induce MMP-2 and MMP-9 production in endothelial cells. In the study of the relationship of the MMP-1 enzyme, TIMP-1 with the Th1 / Th2 cytokine pathway in the blood of normal people, there was a correlation between TIMP1 and serum IL-5 and IL-8 levels [21].

In the examination of IL-17A cytokines, the mean expression of IL-17A on IHC was $88.2 \%$ $( \pm 16.8)$, and ELISA was $25.6 \mathrm{pg} / \mathrm{ml}( \pm 22.7)$. In 2011, Derycke et al. conducted a IL-17A study as a neutrophil regulator, which found IL-17A expression on IL-5 positive nasal polyps was $16.4 \mathrm{pg} / \mathrm{ml}$ while in IL-5 negative nasal polyps was $41.1 \mathrm{pg} / \mathrm{ml} .{ }^{22} \mathrm{IL}-17 \mathrm{~A}$ indirectly activates neutrophils and Th17 cells can activate neutrophils by releasing GM-SCF, interferon- $\gamma$ or TNF$\alpha$. The study by Zhang et al reported on the Chinese population clearly showing significant Th1 / Th17 polarization with significantly elevated levels of IL-17A and interferon. ${ }^{23}$ Bachert also reported the same thing in Asia where it was more likely to have Th1 polarization / Th17. ${ }^{8} \mathrm{IL}-$ 17A is an induction of proinflammatory cytokines (such as IL-1, IL-6, and TNF- $\alpha$ ), chemokines (CXCL1, CXCL2, CXCL5, and CXCL8) and adhesion molecules (ICAM-1 and VCAM-1) by epithelial and endothelial cells, thus causing recruitment of inflammatory cells and increasing the interaction of these cells with the epithelium which causes an excessive in the local inflammatory process [1],[24].

However, there was no significant correlation between IHC examination and ELISA examination in IL-8 and IL-17, and both of them had a negative correlation. There was a variability inflammatory expression in a nasal polyp. Another study examined the correlation between levels of inflammatory mediators measured in nasal lavage fluid versus nasal polyp tissue within the same individuals. Of the 20 mediators evaluated, only IL-10 was found to have a significant and positive correlation between nasal lavage and polyp tissue. This finding supports a previous observation that there is regional variability in inflammatory mediator expression within a single sinonasal cavity. ${ }^{25,26}$ The histological characteristics of the mucosa and the inflammatory cells in sinus exudate depend on the allergic status. Neutrophils are predominant in the sinus fluid of patients with CRS, but a low percentage of eosinophils, mast cells and basophils may also be observed. IL-8 had a high concentration in the nasal discharge of patients with CRS [16].

Each of IHC and ELISA examination has its advantages and disadvantages. The ELISA examination method is an objective quantitative examination at the level of analysis, and IHC examination produces semi-quantitative information and is more subjective than ELISA 
because IHC examination is calculated manually by human labor. However, IHC examination can evaluate tissue heterogeneity. Furthermore, the distribution of antigens in different cells and the clinical relevance of antigen expression in certain cell types can be studied on IHC examination [27]. On ELISA examination, samples were taken using brushing techniques on the mucosal surface of polyps that were easy to apply, more comfortable and faster. However, this technique can only take mucosal surface cytology. While IHC examination is performed on polyp tissue in the form of paraffin blocks. The degree of match between the two examination techniques can explain the position of each examination between each other.

\section{Conclusion}

Our understanding of NP has advanced in recent years, many different diseases are affecting the sinus tissue. There was a variability inflammatory expression between mucosal dan tissues. In this study, there was no significant correlation between IHC examination on polyp tissue and ELISA examination on mucosa, but there was a positive correlation in IL-5. Mucosal brushing technique can represent IL-5 in tissues as a convenient and non-invasive examination. Further research is needed to find out the most convenient and non-invasive method to determine the pattern of inflammatory CRSwNP and early diagnosis. Early diagnosis may benefit the treatment strategies for the management of CRSwNP patients.

\section{References}

[1] Van Zele T, Holtappels G, Gevaert P, Bachert C. Differences in initial immunoprofiles between recurrent and nonrecurrent chronic rhinosinusitis with nasal polyps. Am J Rhinol Allergy. 2014;28(3):192-8.

[2] Tomassen P, Vandeplas G, Van Zele T, Cardell LO, Arebro J, Olze H, et al. Inflammatory endotypes of chronic rhinosinusitis based on cluster analysis of biomarkers. J Allergy Clin Immunol. 2016;137(5):1449-1456e4.

[3] Eloy P, Poirrier AL, De Dorlodot C, Van Zele T, Watelet JB, Bertrand B. Actual concepts in rhinosinusitis: A review of clinical presentations, inflammatory pathways, cytokine profiles, remodeling, and management. Curr Allergy Asthma Rep. 2011;11(2):146-62.

[4] Hsu J, Peters AT. Pathophysiology of chronic rhinosinusitis with nasal polyp. Am J Rhinol Allergy. 2011;25(5):285-90.

[5] Kösem M, Bulut G, Kaya Z. Analysis of Ki-67 immunoreactivity in recurring and nonrecurring nasal polyps. J Otolaryngol - Head Neck Surg. 2010;39(4):464-7.

[6] Tosun F, Arslan HH, Karslioglu Y, Deveci MS, Durmaz A. Relationship between postoperative recurrence rate and eosinophil density of nasal polyps. Ann Otol Rhinol Laryngol. 2010;119(7):455-9.

[7] Bachert C. Evidence-based management of nasal polyposis by intranasal corticosteroids: From the cause to the clinic. Int Arch Allergy Immunol. 2011;155(4):309-21.

[8] Bachert C, Pawankar R, Zhang L, Bunnag C, Fokkens WJ, Hamilos DL, et al. ICON: Chronic rhinosinusitis. World Allergy Organ J. 2014;7(1):1-28.

[9] Zhang N, Van Zele T, Perez-Novo C, Van Bruaene N, Holtappels G, DeRuyck N, et al. Different types of T-effector cells orchestrate mucosal inflammation in chronic sinus disease. J Allergy Clin Immunol. 2008;122(5):961-8.

[10] Fokkens et al. European Position Paper on Rhinosinusitis and Nasal Polyps. Rhinology. 2012;50(23).

[11] Perić A, Vojvodić D, Vukomanović-Durdević B, Baletić N. Eosinophilic inflammation in allergic rhinitis and nasal polyposis. Arh Hig Rada Toksikol. 2011;62(4):341-8. 
[12] Rinia AB, Kostamo K, Ebbens FA, Van Drunen CM, Fokkens WJ. Nasal polyposis: A cellularbased approach to answering questions. Allergy Eur J Allergy Clin Immunol. 2007;62(4):348-58.

[13] [Van Crombruggen K, Zhang N, Gevaert P, Tomassen P, Bachert C. Pathogenesis of chronic rhinosinusitis: Inflammation. J Allergy Clin Immunol. 2011;128(4):728-32.

[14] Anselmo-lima WT, Gallego AJ, Cavallari FE, Küpper DS, Milanezi C, Silva JS, et al. IL-5 , IL-8 and tgf-beta expressions in chronic rhinosinusitis patients with nasal polyps and their correlation to tissue 's cellularity and disease relapsing. Clin Transl Allergy. 2013;3(Suppl 2):2013.

[15] Bachert C, Zhang N, Holtappels G, De Lobel L, Van Cauwenberge P, Liu S, et al. Presence of IL5 protein and IgE antibodies to staphylococcal enterotoxins in nasal polyps is associated with comorbid asthma. J Allergy Clin Immunol. 2010;126(5):962-968.e6.

[16] Pawankar R, Nonaka M, Masuno S, Kimura S. Current concepts on the pathomechanisms of chronic rhinosinusitis and nasal polyps. In: Onerci TM, J.Ferguson B, editors. Nasal Polyposis : Phatogenesis, Medical and Surgical Treatment. London: Springer-Verlag Berlin Heidelberg; 2010. p. $185-8$.

[17] Zhang Y, Gevaert E, Lou H, Wang X, Zhang L, Bachert C, et al. Chronic rhinosinusitis in Asia. J Allergy Clin Immunol. 2017;140(5):1230-9.

[18] Allen JS, Eisma R, Leonard G, Lafreniere D, Kreutzer D. Interleukin-8 expression in human nasal polyps. Otolaryngol Head Neck Surg. 1997;117(5):535-41.

[19] Ikeda K, Shiozawa A, Ono N, Kusunoki T, Hirotsu M, Homma H, et al. Subclassification of chronic rhinosinusitis with nasal polyp based on eosinophil and neutrophil. Laryngoscope. 2013;123(11):1-9.

[20] Wen W, Liu W, Zhang L, Bai J, Fan Y, Xia W, et al. Increased neutrophilia in nasal polyps reduces the response to oral corticosteroid therapy. J Allergy Clin Immunol. 2012;129(6):1522-8.

[21] Chen YS, Langhammer T, Westhofen M, Lorenzen J. Relationship between matrix metalloproteinases MMP-2, MMP-9, tissue inhibitor of matrix metalloproteinases-1 and IL-5, IL8 in nasal polyps. Allergy Eur J Allergy Clin Immunol. 2007;62(1):66-72.

[22] Derycke L, Zhang N, Holtappels G, Dutré T, Bachert C. IL-17A as a regulator of neutrophil survival in nasal polyp disease of patients with and without cystic fibrosis. J Cyst Fibros. 2012;11(3):193-200

[23] Zhang N, Van Zele T, Perez-Novo C, Van Bruaene N, Holtappels G, DeRuyck N, et al. Different types of T-effector cells orchestrate mucosal inflammation in chronic sinus disease. J Allergy Clin Immunol. 2008;122(5):961-8.

[24] Avelino MAG, Wastowski IJ, Ferri RG, Elias TGA, Lima APL, Nunes LM, et al. Interleukin-17A expression in patients presenting with nasal polyposis. Braz J Otorhinolaryngol. 2013;79(5):6169.

[25] Stevens WW, Ocampo CJ, Berdnikovs S, Sakashita M, Mahdavinia M, Suh L, et al. Cytokines in Chronic Rhinosinusitis Role in Eosinophilia and Aspirin-exacerbated Respiratory Disease. 2015;192(6):682-94.

[26] Stevens WW, Schleimer RP, Kern RC. Chronic Rhinosinusitis with Nasal Polyps. J Allergy Clin Immunol Pract. 2018;4(4):565-72.

[27] Ferrier CM, Witte HH De, Straatman H, Tienoven DH Van, Geloof WL Van, Rietveld FJR, et al. Comparison of immunohistochemistry with immunoassay ( ELISA) for the detection of components of the plasminogen activation system in human tumour tissue. 1999;79:1534-41. 